\title{
Level-based and Web-assisted College English Teaching Model
}

\author{
Ling Yi Huang \\ College of Foreign Languages and Cultures, Xiamen University, China \\ ilovexmu2015@126.com
}

Keywords: Level-based; Web-assisted; College English; Teaching Model; Language Learning

\begin{abstract}
College English Teaching Reform in Xiamen University has undergone several changes since 2005. The current level-based and web-assisted model has been implemented in view of the changing needs of both teachers and students. A survey has been conducted to find out the students' view of the current model, whose result will give an insight into the model itself and the possible problems it incurs. Suggestion will be made and improvement can be done in following adjustments.
\end{abstract}

\section{Introduction}

College English teaching reform has always been a hot issue in the whole Course Restructuring Practice in Chinese universities. When the enrollment expansion accelerated in recent years, Chinese universities face increasing pressure both in teaching model reforms and maintaining quality. The ever-increasing number of college students brings not only the problem of how to meet the proper ratio of student-teacher, but also the problem of how to balance the different levels of students in one big class.

\section{Level-based Teaching Model}

The "input hypothesis" put forward by Stephen Krashen states that learners make progress in the language learning process when they comprehend the input that is slightly more advanced than their original level. This level of input is called " $1+1$ ", where " 1 " is the language input and " +1 " is the next stage of language acquisition [1] [2]. This hypothesis means in the language learning process, the language input level should be slightly higher than the students' level, yet in face of a big class with diverse levels, teachers would find great difficulties in finding the proper level and maintaining teaching quality.

Xiamen University is one of the key universities in China. Although its annual enrollment of undergraduate students remain at 5000, it is a still big pressure on the Department of College English Teaching when the ratio of teacher and student is taken into consideration. The number of Teachers responsible for undergraduates is no more than 60,so most of the classes have up to 45-55 students. Also, China's special educational system which caters to its big territory leads to a big gap in English Teaching level in middle school. Students from different provinces have totally diverse English proficiency in both listening and speaking and writing. The traditional way of classification cannot meet the requirement of language teaching and would become an obstacle to further improvement.

The Ministry of Education in China laid out the "College English Course Teaching Requirement" in 2004 and further amended it in 2007 [3]. It points out that the teaching objectives of College English should foster students' practical ability in language use, which means that the teaching model should be changed from teacher-centered to student-centered. And in the age of Internet, this teaching model would be propelled by the internet technology. [4]

In view of these changing situation, the Department of College English Teaching began the first reform in 2005 and tried to place students in different levels according to their level-placement exam results. The first trial was experimental due to a lack of former experiences. Students were only divided into two levels: normal-level class and improved-level class. The improved level had only 
800 students and were assigned to only 4 teachers. Compared with the 5000 base, it could only be understood as an attempt to experiment.

Year 2012 saw two important changes: the moving back to the main campus that make further changes possible and web-assisted infrastructures were bought and implemented. Therefore, from this year, the annual level-placement exam result plays a more crucial role: put 5000 students into 4 different categories (increase to 5 categories in 2013). Each level have different requirement of learning length and content.(see Table 1).

Table 1.Level-based College English Teaching Mode 1 (2013)

\begin{tabular}{|c|c|c|c|c|}
\hline \multirow{2}{*}{ Level } & \multicolumn{2}{|l|}{ First Year } & \multicolumn{2}{|l|}{ Second Year } \\
\hline & First Term & Second Term & Third Term & Fourth Term \\
\hline Preliminary level & Preliminary Course & $\begin{array}{l}\text { Integrated } \\
\text { English One }\end{array}$ & $\begin{array}{l}\text { Integrated } \\
\text { English Two }\end{array}$ & $\begin{array}{l}\text { Integrated } \\
\text { English Three }\end{array}$ \\
\hline Level One & $\begin{array}{l}\text { Integrated English } \\
\text { One }\end{array}$ & $\begin{array}{l}\text { Integrated } \\
\text { English Two }\end{array}$ & $\begin{array}{l}\text { Integrated } \\
\text { English Three }\end{array}$ & $\begin{array}{l}\text { Improved } \\
\text { Course }\end{array}$ \\
\hline Level Two & $\begin{array}{l}\text { Integrated English } \\
\text { Two }\end{array}$ & $\begin{array}{l}\text { Integrated } \\
\text { English Three }\end{array}$ & $\begin{array}{l}\text { Improved } \\
\text { Course }\end{array}$ & \\
\hline Level Three & $\begin{array}{l}\text { Integrated English } \\
\text { Three }\end{array}$ & $\begin{array}{l}\text { Improved } \\
\text { Course }\end{array}$ & Selective Course & \\
\hline Level Four & $\begin{array}{l}\text { Improved } \\
\text { Course }\end{array}$ & Selective Course & & \\
\hline
\end{tabular}

* Jiang, College English Syllabus of Xiamen University,2013 [5].

Level placement exam place students of similar abilities in the same level and varied teaching contents ensure the students can have the ability to cope with the learning materials.

\section{Web-assisted Teaching Model}

The great gap between the demand and supply of the teachers (5000 students VS 50+ teachers) pushes the acceleration of the implementation of Web-assisted Teaching Model.

Web-assisted Teaching Model in Xiamen Universities is based on the " $2+2$ Course reform". When students take a 2-hour face-to-face in-class lesson, they should also complete a 2-hour assignment and other interactive activities after the class. This reform gives both the teacher and student more free time to fulfill the learning goal. The teachers need to plan well ahead the whole week's assignment and materials, while the students should put more efforts and take more initiative in taking up the after-class activities. And most importantly, most of these new practices are assisted by internet and software.

For writing assignment, students should log on the website-www.pigai.org to finish the bi-weekly composition. Teachers only have to give the requirement on website and wait for the final results to come up. Students have unlimited chances to revise the paper until the final deadline and can get instant score and comment right after he submits the paper. The website also provides a big database that can give grammatical check, writing suggestions and other linguistic helps. The unlimited revising chances give the students strong impetus to further improve their articles and the interactive linguistic checking helper greatly relieve the teachers' burden. Of course the teacher would give their comment afterwards, but the simple grammatical checks have been done by the machine, thus saving time and efforts.

For other practicing needs, Xiamen University has set up a website to provide different forms of English learning exercises, such as linguistic quizzes, exercises, reading comprehension, vocabulary building-up, Band Four or Six Model Test, IELTS or TOFEL Model Test, etc. All these exercises are provided for free and students can choose different stages according to their levels. All the practice scores will be recorded automatically and can be provided as a reference as students' after-class performance .

For the convenience of timely communication between the students and teachers ,every class has set up a QQ group. The instant communicative device facilitates the communication and caters to the 
students' needs in the age of Internet. This greatly reduces the disadvantages the insufficient meeting time incurs.

\section{College English Reform Survey}

All these practices are designed and implemented according to the real situation in Xiamen University. After years of practice it would be necessary to find out the reaction and level of satisfaction from students' part.

The survey titled "Survey of College English Teaching" was designed in an aim to find out the reactions of students to the present level-based and web-assisted College English Teaching model and give reflections on the current model design and find out reasons behind those possible dissatisfactions.

The survey was conducted in July 2013 and was posted on an online survey website www.sojump.com. Questions were designed focusing on the issue of the current teaching model. 218 students ranging from first year to fourth year answered the survey.

Findings. Of 218 students, the first, second, third, fourth year students account for $30.73 \%$, $40.83 \%, 5.05 \%, 23.4 \%$ of the total respectively. Therefore the majority of the students surveyed were first and second year students who have more experience and understanding of the current teaching model (the model underwent several changes and became stable from 2012).

Most students were placed at Level One (55.05\%) and Level Two (33.94\%), which was consistent with the design of the level-based system which place most students in the basic levels.

Level-based Teaching Model . To our delight, over $85.78 \%$ of students believed that the current level-based teaching model was necessary (35.78\% felt very necessary and $50 \%$ felt necessary).The reason may be manifested in their answer to "the adjustment to the level-based teaching model". $26.15 \%$ of the students said they were well adjusted to the model, $61.47 \%$ said they were basically adjusted, only $12.39 \%$ felt that they didn't adjust to this model.

But to our surprise, although students confirmed the necessity of a level-based teaching model, they didn't feel the positive impact it brings to the learning. Only $33.49 \%$ of the students said they agreed that level-based model had enhanced their enthusiasm, while others $(38.91 \%)$ said this model did not or even hurt their enthusiasm (8.26\%). Similarly, only $19.27 \%$ confirmed the positive influence of the model on their studies, and the rest felt either no obvious impact (61.47\%) or no help at all (19.27\%).

The fact that a large percentage of students feel the necessity of level-based teaching model give us a great relief that we move in the correct direction.

The large number of enrollment cannot be changed overnight and so do the diverse levels of English. The level-based model give students enough room to improve their English, recognizing the differences in their starting point. Student who have higher proficiency can have more chances to select courses ranging from literature to business English. On the other hand, students that have difficulties in listening and speaking have more time to make improvement and will not be deprived of the opportunity to show their talent when the rest of the class are of the similar level.

Teachers will also be the beneficiary of this model — because they can make teaching plans purely based on the level, without the distraction if class is made up of students with different levels and diverse requirements.

But we have to admit that still there was a considerable number of students that show their dissatisfaction in the encouragement function the model should have. Only $22.02 \%$ of the students thought the level-based model have a positive impact on students performance in class and encouraged fair competition. $11.01 \%$ said it was of no use, $55.05 \%$ felt little use and $4.59 \%$ said it had exerted negative reactions. When asked about its impact on students' psychology, only 38.99\% thought the level-based model have a positive psychological impact, $28.9 \%$ asserted that it brought negative influence psychologically. And this phenomenon is also observed and warned by many scholars. [6] [7] [8] [9] [10] 
These answers seemed paradoxical, yet it raised the questions why most students felt it was necessary to have a level-based teaching model but fail to benefit enough from it.

After further research, we find out some possible reasons that may account for the problem. The current level-based teaching model largely depends on the level-placement test students took right after they went into the college. One exam result decides which level you will be in. And because of the complexity of structure inside the university, this model now cannot provide enough flowing inside the model. Students who fail the exam will not go down to the lower level. They just move on with the previous level and to take a make-up course designed for all those who failed in the exam. And for students who work hard and get high scores do not have enough chances to " jump" to a higher grade. The "Jumping-the-grade" exam is held only once a year and only few students can get the qualification to apply for the exam. This greatly suppress the impetus the level-based teaching model should exert and fail to encourage students to make efforts to self-improve. Without an aim and without the possible way-out, students may feel content with their current situation and give up the initiative in moving forward.

Web -assisted Teaching Model Welcomed. Although to some students, it still takes time to adjust to the model of writing articles and doing exercises online, most of the students expressed their support of the coming new technology. 35.2\% said they felt very comfortable with the new technology-based model, $30.7 \%$ said they felt comfortable, only $16 \%$ said they were uncomfortable with the new style, and $18.1 \%$ said they felt no difference.

The top three advantages of the new web-assisted model recognized by students are providing interaction instantly $(73.39 \%)$, giving more choices $(70.64 \%)$, have closer links with classmates $(56.88 \%)$. These mostly can be traced to the functions provided by online writing system-pigai.org, online English Practice website, and QQ group. Through the online writing system, students can practice writing anytime, anywhere, for unlimited times and get feedback instantly. Most students revised their articles for at least 6 times [11] and the most diligent student in my class revised one article for 212 times, which cannot be expected if it is written on paper. And the online English Practice website give students enough freedom to choose the exercises according to their level and bring their own initiative into full play. And the QQ groups set up the platform for students to communicate with others and the after-class group work assigned by teachers gives the students chances to cooperate with classmates from other departments and form a good learning environment.

The Web-assisted Teaching Model is based on the technology of network, which requires enough hardware and software. For some freshmen, it would be a financial burden to purchase the computer right away. Although the university offers free computer rooms, it is still a "digital gap" between students who already own computers and have been skillful at it and those who don't. And we cannot overlook the psychological impact on these part of the students.

When asked about the problem students encounter in finishing the web-assisted tasks, $45.8 \%$ of the students said they find it hard to adjust to doing exercises on computer,47.24\% said that they do not have sufficient time to communicate with teachers, and $29.83 \%$ said the technology clichés annoy them sometimes.

This again raised the problem of face-to-face communication or web interaction. How to balance the time spent in class and after-class would be a big problem for teachers in years ahead. In face of current situation with expanding student lists and increasing research burden, we could not expect teachers to have more time with students face-to-face, and with the popularity of Mooc, more courses would be offered on Internet and students have to adjust to this new trends, irrespective of their willingness. Of course, teachers can offer more technical help at the beginning of the course and universities can provide more free access to computers, reducing the burden of financially-needed students. 


\section{Conclusions}

After years of implementation, the level-based and web-assisted College English Teaching Model have been accepted by both students and teachers.

Although we must admit that there are still problems to solve and improvement to make, the current teaching model is in line with the cognitive rule of the language learning and reflect the needs of the age of internet.

Adjustment should be made to the flowing way inside the level system to give enough encouragement and pressure to the students. Technology should be used, but to what extent it is used is the problem that needs to be further analyzed.

\section{References}

[1] Krashen, S.D. Second Language Acquisition and Second Language Learning. Oxford: Pergamon.1981:213.

[2] Xing Zou. The Graded College English Teaching Guided by The Theory of " $1+1$ ". School of Foreign languages. Wuhan Polytechnic University,2012.

[3] Ministry of Education. College English Course Teaching Requirement. Beijing: Higher Education Publishing House.2007.

[4] Schunk. D. H. Learning Theories: An Educational Perspective. Nanjing: Jiangsu Education press.2000.

[5]Jiang, G.Y. College English Syllabus of Xiamen University. Xiamen: Xiamen University Press.2013.

[6] Xu Ying. Problems in The Level-based College English Teaching. Modern Communication. 2013(10).

[7] Chen H.F. \& Li X.J. Reflections and Coping Tactics in The Level-based College English Teaching. Journal of Jin Lin College of Business Management .2012(28):05.

[8] Zhu C. Phychology of Foreign Language Teaching.Shanghai: Shanghai Foreign language Educaiton Press.2004.

[9] Xu Na. Problems and Coping Tactics in Graded College English Teaching. Jin Ri Ke Yan.2010(4):197.

[10] Liu X.Q. Reflections on The Level-based College English Teaching, Science and Technology Information.2011(13).

[11] Report on the Use of Pigai.org in Xiamen University ,2014. 